\title{
Serum Level of pro Brain Type Natriuretic Peptide in Diuretic Resistance and Diuretic Respondent Ascites in Cirrhotic Patients
}

\author{
E mail: \\ erhhnoh@yahoo.com
}

Received :5/8/2012

Accepted after

revision:26/9/2012

Key words: Diuretic

resistance

ascitis, diuretic

respondent,

Natriuretic peptide, Pro BNP

\author{
Ehab F Mostafa ${ }^{1}$, Emad F Hamed ${ }^{1}$, Marawan M Atiyah', \\ Hoda A Hagrass ${ }^{2}$ \\ ${ }^{I}$ Internal Medicine Depatrment,Faculty of Medicine, Zagazig University, Egypt \\ ${ }^{2}$ Clinical Pathology Department,Faculty of Medicne, Zagazig University, Egypt
}

Background and Study aim: Diuretic Results: There was no significant resistance in patients with cirrhosis is clinically manifested by the failure to lose weight or ascetic volume despite high dosages of loop diuretics and sodium restriction. Natriuretic peptides(NP) promote natriuresis and diuresis. Atrial natriuretic peptide (ANP) is known to act as a rapid response hormone and Brain natriuretic peptide( BNP) more as a "back up hormone" activated only after prolonged ventricular overload .Pro BNP are more stable and have been suggested to have a longer biological half life than other natriuretic peptides .

The aim of this work is to study the effect of vascular volume on serum level of Pro BNP and to find out the difference of serum level of pro BNP in both diuretic resistant and diuretic responder ascites.

Patients and Methods: The study was conducted on 89 patients. Patients subdivided into 2 groups :group 1(41 patients) described as diuretic resistance ascites and group 2 (48 patients) as diuretic respondent.In which both groups underwent laboratory and echocardiography study . NT-proBNP were measured by electrochemiluminescence immunoassay "ECLIA", Doppler echocardiography by using a System FiVe digital ultrasound machine.

difference between the groups as regards age, serum potassium, liver enzymes, serum bilirubin, total proteins, international normalized ratio or partial thromboplastin time. The following parameters were significantly lower in the diuretic-resistant group: serum albumin and platelet count. However, the diureticresistant patients had higher blood urea nitrogen (BUN), serum creatinine and higher Child score. There were significant differences between both groups regarding serum level of pro BNP, serum and urinary NA, left atrial dimension (LAD) and left ventricular end diastolic dimension (LVEDD) in which all parameter were higher in diuretic respondent versus resistant group. Also significant positive correlation was noted between Pro BNP and serum and Urinary NA, LAD and LVEDD.

Conclusion: Pro BNP is higher in diuretic responder than in diuretic resistance group, and although the latter group has a higher level of Pro BNP than the cut off point but it is not enough to induce diuresis. Also we found that decrease intravascular compartment may decrease cardiac chamber expansion with subsequent decrease in the level of natriuretic peptide leading to decrease the response of diuretic.

\section{INTRODUCTION}

Liver cirrhosis is a frequent consequence of the long clinical course of all chronic liver diseases (CLD) characterized by parenchymal damage [1, 2, 3].

Patients with cirrhosis and portal hypertension typically develop altered extracellular volume regulation with renal sodium and water retention. This eventually leads to the development of ascites, which is the most common of the major complications of cirrhosis $[4,5,6]$.
Diuretic resistance in patients with cirrhosis has been variably defined but clinically is manifested by the failure to lose weight or ascetic volume despite high dosages of loop diuretics and sodium restriction, a functional definition of diuretic resistance is based upon the failure to increase 24-h urine sodium excretion to greater than $78 \mathrm{meq} /$ day despite high-dose diuretics[6].

Diuretic resistance has several potential etiologies including high dietary sodium intake, poor intestinal 
absorption of the diuretic, decreased glomelural filtration rate (GFR) and decreased renal blood flow with resulting decreased drug entry in the tubule lumen, proteinuria with decreased concentration of free diuretic in the tubule lumen $[7,8]$.The endocrine nature of the heart was first understood with the description of atrial natriuretic peptide (ANP) [9] and later detection of brain (B-type) natriuretic peptide(BNP), which is mainly released from the myocardium in humans[10,11,12]. B-type natriuretic peptide has similar biological effects to ANP. Both are produced primarily in the atria under normal conditions [13].

Natriuretic peptides promote natriuresis and diuresis, vasodilatation, and antagonize the effects of the renin-angiotensin-aldosterone and sympathetic nervous systems [14,15]. In the central nervous system, natriuretic peptides act as neurotransmitters and decrease sympathetic tone, reduce secretion of arginine-vasopressin and corticotrophin, and inhibit salt appetite and water drinking [16]. Natriuretic peptides modulate myocardial and vascular structure and function via antiproliferative and cytoprotective effects $[14,15,17]$.

In response to cardiac pathologies with pressure or volume overload, ventricular myocytes reexpress foetal genes including ANP and BNP. Then, most of the BNP is released from the ventricles [13]. NPs are increased in all oedematous disorders with salt and fluid overload and those with increased atrial or ventricular wall tension, e.g. in heart failure, renal failure and liver cirrhosis[14].

In cirrhosis, intestinal flora disorder, the transition of intestinal flora to mesenteric lymph nodes, bacterial translocation, and decreased hepatic clearance of endotoxins cause an endotoxemic medium. Consequently, various mediators (nitric oxide, von Willebrand factor (VWF), etc.) are released from endothelial cells and a hyperdynamic circulation occurs $[18,19]$. These changes result in functional and structural cardiac disorders in patients with liver cirrhosis [20].

Atrial natriuretic peptide (ANP) is known to act as a rapid response hormone and BNP more as a "back up hormone" activated only after prolonged ventricular overload [21]. The biological effects of ANP and BNP are natriuresis, diuresis, and vascular relaxation, but patients with cirrhosis, especially with advanced disease, may be resistant to these effects [22].

The larger $\mathrm{N}$ terminal prohormone fragments of proBNP are more stable and have been suggested to have a longer biological half life. Finally, the requirements for blood sampling are less critical. Circulating proBNP concentration is less sensitive to rapid fluctuations caused by short term stimuli of secretion, such as change in body posture, exercise, or volume changes. ProBNP has therefore been suggested as an even better marker of heart failure or volume change than BNP [23].

Our present research tries to detect the effect of vascular volume on serum level of Pro BNP and to find out the difference of serum level of pro BNP in both diuretic resistant and diuretic responders ascites.

\section{PATIENTS AND METHODS}

From October 2011 to March 2012, the study was conducted on 89 patients (58 male and 31 female; mean age $50 \pm 4.5$ years) with liver cirrhosis and ascites, who were followed up in outpatient's clinics of Department of Internal Medicine in Zagazig University Hospitals. Liver cirrhosis was documented by clinical assessment, laboratory findings and evidence of liver cirrhosis upon abdominal ultrasound. Ascetic fluid analysis was done. Patients with evidence of portosystemic encephalopathy or intrinsic renal disease were excluded from the study, none of the patients had experienced recent gastrointestinal bleeding, none had signs of heart failure, diabetes, cancer, or any other major disease, and all patients had normal kidneys upon ultrasound and no proteinuria or active urinary sediment upon urine analysis. All patients kept under absolute salt restriction, additional cardiovascular medication, including beta blockers, was not prescribed for any of the patients. All patients had normal cardiac physical examination, and in those who had a chest $x$ ray performed, signs of cardiomegaly were absent.

No evidence of heart failure by Echocardiography and ECG showed normal configurations apart from sporadic extrasystoles in some patients

Patients subdivided into 2 groups, (group1with 41 patients) described as diuretic resistance 
ascites and (group 2 with 48 patients) as diuretic responders.

Criteria of diuretic resistance ascites were fulfilled according to Revised Diagnostic Criteria of Resistance Ascites (International Ascites Club)[24].

1. Treatment duration: patients must be on intensive diuretic therapy (spironolactone $400 \mathrm{mg}$ by mouth daily and furosemide 160 mg by mouth daily) for at least 1 week and on sodium restricted diet of less than 90 $\mathrm{mmol} / \mathrm{L}$ per day or $5.2 \mathrm{~g}$ of salt $(\mathrm{NaCl})$ per day.

2. Lack of response: mean weight loss of $<0.8$ $\mathrm{kg}$ over 4 days and urinary sodium output less than the sodium intake.

3. Early ascites recurrence: reappearance of grade 2 or 3 ascites within 4 weeks of initial mobilization.

4. Diuretic-induced complications

a. Diuretic-induced hepatic encephalopathy: development of encephalopathy in the absence of any other precipitating factor.

b. Diuretic-induced renal impairment: increase of serum creatinine by $>100 \%$ to a value $>2$ $\mathrm{mg} / \mathrm{dL}$ in patients with ascites responding to diuretics.

c. Diuretic-induced hyponatremia: decrease of serum sodium by $>10 \mathrm{mmol} / \mathrm{L}$ to a serum sodium of $<125 \mathrm{mmol} / \mathrm{L}$.

d. Diuretic-induced hypo- or hyperkalemia: change in serum potassium to $<3 \mathrm{mmol} / \mathrm{L}$ or $>6 \mathrm{mmol} / \mathrm{L}$ despite appropriate measures

On the other hand group 2 has proper weight reduction with dose less than maximum dose of diuretics.

Collection of 24-h urine sample for calculation of sodium was done in sterile plastic containers by recording the volume in $24 \mathrm{~h}$, starting at 08:00. Verbal instructions were given to assure completeness of collection. Samples were centrifuged and sodium concentration was measured in $\mathrm{mEq} / \mathrm{L}$ using a Beckman Synchron CX5 ISE (NJ, USA) chemistry analyzer. All samples were processed on the day of collection. In order to obtain the whole 24-h urinary sodium, we multiplied sodium concentration by the volume in liters.

NT-proBNP were measured by electrochemiluminescence immunoassay "ECLIA" at Zagazig university hospitals on the Roche cobas e immunoassay analyzers (Roche Diagnostics, Inc., Indianapolis, IN).

Doppler echocardiography by using a System FiVe digital ultrasound machine (GE Vingmed Ultrasound) with a combined tissue imaging (2.5- to 3.5-MHz) and Doppler (2.75-MHz) transducer was done for all patients excluding any cardiac lesion or evidence of heart failure.

\section{Statistical analysis:}

Data were collected, revised, verified and edited on a PC. Data were then analyzed statistically using SPSS statistical package version 19 (SPSS, Chicago, IL, USA). Data were reported in the form of mean $\pm \mathrm{SD}$. Student's $t$ test was used to compare the interval variables. Correlation between 24-h urinary sodium and other variables was done using Pearson correlation.

\section{RESULTS}

As shown in Table1, there was no significant difference between the groups as regards age, serum potassium, liver enzymes, serum bilirubin, total proteins, international normalized ratio or partial thromboplastin time. The following parameters were significantly lower in the diuretic-resistant group: serum albumin and platelet count. However, the diuretic-resistant patients had higher blood urea nitrogen (BUN), serum creatinine and higher Child score. Table 2, showed significant difference between both groups regarding serum level of pro BNP, serum $\mathrm{Na}(121 \pm 8.2,132 \pm 5)$, urinary sodium(35.2 $\pm 8.2,125 . \pm 8)$, LAD $(36.2 \pm 4.3,38.8 \pm 4.6)$ and $\operatorname{LVEDD}(46.3 \pm 1.8,48.4 \pm 3.1)$. 'Table 3, showed Significant positive correlation was noted between Pro BNP and serum NA $(r=$ $0.841, P=0.001)$, Urinary NA $(r=0.741, P=$ $0.001)$, LAD $(r=0.630, P=0.001)$ and $\operatorname{LVEDD}(r=0.561, P=0.001)$. 
Table (1): Patients characteristics (mean \pm SD)

\begin{tabular}{|l|c|c|c|}
\hline & $\begin{array}{c}\text { Diuretic-resistant group } \\
(\boldsymbol{n}=\mathbf{4 1})\end{array}$ & $\begin{array}{c}\text { Diuretic-respondent } \\
\text { group }(\boldsymbol{n}=\mathbf{4 8})\end{array}$ & $\boldsymbol{P}$ \\
\hline Age $(\mathrm{yr})$ & $50 \pm 4$ & $49 \pm 4$ & $\mathrm{NS}$ \\
\hline Serum creatinine $(\mathrm{mg} / \mathrm{dL})$ & $1.2 \pm 0.8$ & $1.0 \pm 0.2$ & 0.043 \\
\hline BUN $(\mathrm{mg} / \mathrm{dL})$ & $45.5 \pm 9.3$ & $19.5 \pm 9.2$ & 0.013 \\
\hline Serum potassium $(\mathrm{mEq} / \mathrm{L})$ & $4.1 \pm 0.7$ & $4.2 \pm 0.6$ & $\mathrm{NS}$ \\
\hline AST $(\mathrm{U} / \mathrm{L})$ & $69 \pm 37$ & $70 \pm 41$ & $\mathrm{NS}$ \\
\hline ALT $(\mathrm{U} / \mathrm{L})$ & $58 \pm 29$ & $57 \pm 37$ & $\mathrm{NS}$ \\
\hline Total bilirubin $(\mathrm{mg} / \mathrm{dL})$ & $2.4 \pm 1.1$ & $2.0 \pm 1.0$ & $\mathrm{NS}$ \\
\hline Direct bilirubin $(\mathrm{mg} / \mathrm{dL})$ & $1.7 \pm 1.1$ & $1.5 \pm 0.9$ & $\mathrm{NS}$ \\
\hline Total proteins $(\mathrm{g} / \mathrm{dL})$ & $7.0 \pm 0.3$ & $7.3 \pm 0.4$ & $\mathrm{NS}$ \\
\hline Serum albumin $(\mathrm{g} / \mathrm{Dl})$ & $2.3 \pm 0.3$ & $2.7 \pm 0.3$ & 0.012 \\
\hline Platelet count $(\times 10 / \mathrm{L})$ & $83 \pm 23$ & $109 \pm 59$ & 0.014 \\
\hline INR & $1.6 \pm 0.5$ & $1.4 \pm 0.3$ & $\mathrm{NS}$ \\
\hline Child classification $(\mathrm{B} / \mathrm{C})$ & $11 / 30$ & $30 / 18$ & 0.011 \\
\hline
\end{tabular}

Table (2): Mean difference \pm SD between both groups regarding serum and urinary Na, Pro BNP, LAD and LVEDD.

\begin{tabular}{|l|c|c|c|}
\hline & $\begin{array}{c}\text { Diuretic-resistant } \\
\text { group }(\boldsymbol{n = 4 1})\end{array}$ & $\begin{array}{c}\text { Diuretic-respondent group } \\
(\boldsymbol{n}=\mathbf{4 8})\end{array}$ & $\boldsymbol{P}$ \\
\hline Serum sodium $(\mathrm{mEq} / \mathrm{L})$ & $121 \pm 8.2$ & $132 \pm 5$ & $\mathbf{0 . 0 0 1}$ \\
\hline Pro BNP(pg/ml) & $256 \pm 82.5$ & $612.3 \pm 249.7$ & 0.001 \\
\hline LAD $(\mathrm{mm})$ & $36.2 \pm 4.3$ & $38.8 \pm 4.6$ & 0.019 \\
\hline LVEDD $(\mathrm{mm})$ & $46.3 \pm 1.8$ & $48.4 \pm 3.1$ & 0.016 \\
\hline 24 hours urinary NA(mEq/L) & $35.2 \pm 8.2$ & $125 . \pm 8$ & 0.001 \\
\hline
\end{tabular}

Table (3): Correlation between serum and urinary Na, LAD and LVEDD with serum Pro BNP in diuretic resistance group.

\begin{tabular}{|l|c|c|c|}
\hline & Mean $(\boldsymbol{n}=\mathbf{4 1})$ & Correlation & $\boldsymbol{P}$ \\
\hline Serum $\mathrm{Na}(\mathrm{mEq} / \mathrm{L})$ & $121 \pm 8.2$ & .841 & 0.001 \\
\hline Urine $\mathrm{Na}(\mathrm{mEq} / \mathrm{L})$ & $35.2 \pm 8.8$ & .741 & 0.001 \\
\hline LAD $(\mathrm{mm})$ & $36.2 \pm 4.3$ & .630 & 0.001 \\
\hline LVEDD $(\mathrm{mm})$ & $46.3 \pm 1.8$ & .561 & 0.001 \\
\hline
\end{tabular}

\section{DISCUSSION}

Approximately $10-20 \%$ of patients with ascites have adequate natriuresis and clinical response to dietary sodium restriction alone, and the majority of the remaining patients respond to diuretic therapy. However, $10 \%$ of patients do not respond to the above measures, or develop complications to diuretic therapy, and these patients are classified as having diuretic resistant ascites [24].

B-type natriuretic peptide (BNP) is a neurohormone synthesized along with atrial natriuretic peptide (ANP) in cardiac ventricles. $\mathrm{BNP}$ is released as preproBNP and then enzymatically cleaved to NT-proBNP and BNP depending on ventricular myocytes stretching and volume overload [25].

NT-proBNP is influenced by age and the age related normal decline in glomerular filtration rate, therefore 2 cutoff points must be used; i.e., NT-proBNP > $125 \mathrm{pg} / \mathrm{mL}$ in patients younger than 75 years and $>250 \mathrm{pg} / \mathrm{mL}$ in patients older than 75 years[26].

Atrial natriuretic peptide (ANP) is known to act as a rapid response hormone and BNP more as a "back up hormone" activated only after prolonged ventricular overload (21). The biological effects of ANP and BNP are natriuresis, diuresis, and vascular relaxation, but patients with cirrhosis, especially with advanced disease, may be partially resistant to these 
effects[22]. The larger $\mathrm{N}$ terminal prohormone fragments of proBNP are more stable and have been suggested to have a longer biological half life. Finally, the requirements for blood sampling are less critical. Circulating proBNP concentration is less sensitive to rapid fluctuations caused by short term stimuli of secretion, such as change in body posture, exercise, or volume changes. ProBNP has therefore been suggested as an even better marker of volume change than BNP [23].

Our present study showed significant difference between serum level of Pro BNP in diuretic resistant $(256 \pm 82.5)$ and diuretic respondent group $(612.3 \pm 249.7)$, in spite of plasma NTproBNP levels were significantly higher in Child class $\mathrm{C}$ than in classes $\mathrm{B}$, supported by Henriksen et al who documented that circulating proBNP concentrations are significantly increased in patients with advanced cirrhosis and that they are closely related to BNP concentrations, however, no signs of reduced hepatic degradation of proBNP or of BNP are present in patients with cirrhosis, suggesting that elevated levels of proBNP and BNP are related to markers of cirrhotic severity[23]. In our study most of patients of diuretic resistant group are of Child class C (30 patients) in contrast to patients of diuretic respondent group (only 18 of total 48 patients), in which this is not matched with Henriksen and Jeong Joo Woo,et al 2008 who documented that Pro BNP is increasing with advanced cirrhosis, but the event in this situation not related only to the severity of the disease but also to other factors[26].

Allan Jaffe, 2003 showed that pressure and volume overload of the cardiac chambers stimulate enhanced production and release of natriuretic peptides. Thus, these peptides reflect the common denominator present in patients with systolic or diastolic dysfunction, volume overload, and HF, regardless of the underlying cardiovascular disease [27], in which this agreed with our study suggested that there are other factors influencing the level of NP in cirrhotic patients.

Our study showed significant difference in serum and urinary NA, LAD and LVEED in both group; diuretic resistance Vs respondent (121 \pm $8,132 \pm 5),(35 \pm 5,125 . \pm 8),(36.2 \pm 4.3,38.8 \pm$ 4.6) and $(46.3 \pm 1.8,48.4 \pm 3.1)$ respectively and also significant positive correlation between these parameter in diuretic resistant group and
Pro BNP, changes in these parameters showed that natriuretic peptides are importantly involved in water and sodium balance and cardiovascular homeostasis [28].

In response to an increase in filling pressures and stretch of the atrial and ventricular walls, atrial natriuretic peptide (ANP) and brain or B-type natriuretic peptide (BNP) are released into the bloodstream [29]. In addition, several neurohormones such as endothelin-1 (ET-1), arginine vasopressin (AVP), and catecholamines stimulate the secretion of natriuretic peptides; this leads primarily to a reduction in preload by increasing water and sodium excretion, but also by shifting plasma from the intravascular to the extravascular space [29]. So the serum and urinary NA reflect the state of intravascular volume, nearly all patient of diuretic resistant group used diuretic for a long period inducing reduction of intravascular volume and decreasing level of both serum and urinary NA and subsequent change of level of natriuretic peptide.

The relationship between LAD or LVEDD was studied by Woo, et al who reported increased serum level of Pro BNP in cirrhotic patients with increased both LAD and LVEDD [26] which agreed with our study. Also this issue reported with Brunner-La Rocca 2001[28]. Natriuretic peptides are importantly involved in water and sodium balance and cardiovascular homeostasis.

In response to an increase in filling pressures and stretch of the atrial and ventricular walls, atrial natriuretic peptide (ANP) and brain or Pro Btype natriuretic peptide (Pro BNP) are released into the bloodstream[29], this explaining the correlation between Pro BNP and both LAD and LVEDD. So decreased intravascular volume may be the key of all events from decreased LAD and LVEDD with subsequent decrease of Pro BNP. In spite of relatively higher level of Pr BNP in diuretic resistant group exceeding the cut-off point $125 \mathrm{pg} / \mathrm{mL}$, but it is not enough to induce diuresis, and may be there is a new cut off point was created and needed to induce diuresis, this may explain that Patients with advanced cirrhosis and ascites have a reduced natriuretic response to natriuretic peptide despite elevated levels[24], in which it apparently clear in diuretic respondent group explaining the big difference in the level of Pro BNP in both group.

From the above we can conclude that Pro BNP is higher in diuretic respondent than in diuretic resistance group, and although the latter group 
has a higher level of Pro BNP than the cut off point but it is not enough to induce diuresis.

Also we found that decrease intravascular compartment may decrease cardiac chamber expansion with subsequent decrease the level of NP leading to decrease the response of diuretic .

So we may expect two options can be used and may be useful to improve diuresis in diuretic resistance, first is intravascular expansion like albumin infusion improving diuresis with increasing plasma oncotic pressure and volume expansion with subsequent cardiac chamber expansion[30] and this may correlate with Wong et al, who showed that (volume expansion or greatly elevated levels of plasma atrial natriuretic factor associated with moderate volume expansion can improve blunted atrial natriuretic factor responsiveness in cirrhotic patients with refractory ascites. This appears to be achieved by way of a marked increase in distal delivery of filtrate in the kidney, with or without activation of distal natriuretic peptide factor receptors in the inner medullary collecting ducts [31]. Other issue concerning with BNP supplementation (Exogenous ANP administration, together with the splanchnic vasoconstrictor terlipressin to counter the hypotensive effect of ANP, increases renal blood flow, GFR and natriuresis in patients with refractory ascites [24].

In theory, the renal effects of natriuretic peptides, if preserved, may help to reduce the pressure in the portal vein. Furthermore, although natriuretic peptides do not seem to have direct effects on hepatic vascular conductance, the reduction in mesenteric blood flow may further contribute to a reduced portal venous pressure. This is in line with other experimental data, which show that natriuretic peptides may reduce portal venous pressure despite loss of renal effects in cirrhotic rats. It remains to be seen whether this is of therapeutic significance in humans with portal hypertension [29].

Funding: Non .

\section{Conflicts of interest: Non .}

Ethical approval: The study was performed according to the ethical standards for human experimentation and was approved by the scientific committee of Zagazig University. Informed consent was obtained from the selected patients after explaining the aim of the study and the nature of the investigations required.

\section{REFERENCES}

1. Anthony PP, Ishak KG. The morphology of cirrhosis. Working group sponsored by the World Health Organization. J Clin Pathol 1978; 31:395-414.

2. Millward-Sadler GH, Hanh EG, Wright R. Cirrhosis: an appraisal. In: Wright R, MillwardSadler GH, Alberti KGMM, Karran S, editors. Liver and biliary disease. 2nd ed. London: Baillière Tindall WB Saunders; 1985. p. 821-60.

3. Rappaport AM, McPhee PJ, Fisher MM, Phillips MJ. The scarring of the liver acini (cirrhosis). Tridimensional and microcirculatory considerations. Virchows Arch 1983;402:107-37.

4. Reichen J, Egger B, Ohara N, Zeltner TB, Zysset T, Zimmermann A. Determinants of hepatic function in liver cirrhosis in the rat. Multivariate analysis. $J$ Clin Invest 1988;82:2069-76.

5. Wanless IR, Wong F, Blendis LM, Greig P, Heathcote EJ, Levy G. Hepatic and portal vein thrombosis in cirrhosis: possible role in development of parenchymal extinction and portal hypertension. Hepatology 1995;21:123847.

6. Runyon BA. Management of adult patients with ascites caused by cirrhosis. Hepatology 1998; 27:264- 72 .

7. Eisenmenger WJ, Blondheim SH, Bongiovanni AM, Kunkel HG. Electrolyte studies on patients with cirrhosis of the liver. $J$ Clin Invest 1950;29:1491-9.

8. Palmer BF. Pathogenesis of ascites and renal salt retention in cirrhosis. $J$ Investig Med 1999;47:183-20.

9. Bold AJ, Borenstein HB, Veress AT, Sonnenberg H. A rapid and potent natriuretic response to intravenous injection of atrial myocardial extract in rats. Life Sci 1981;28:8994.

10. Sudoh T, Kangawa K, Minamino N, Matsuo H. A new natriuretic peptide in porcine brain. Nature 1988;332:78-81.

11. Sudoh T, Minamino N, Kangawa K, Matsuo H. Brain natriuretic peptide-32: Nterminal six amino acid extended form of brain natriuretic peptide identified in porcine brain. Biochem Biophys Res Commun 1988;155:726-732.

12. Yasue H, Yoshimura M, Sumida H, Kikuta K, Kugiyama K, Jougasaki M et al. Localization and mechanism of secretion of B-type natriuretic peptide in comparison with those of A-type natriuretic peptide in normal subjects and patients with heart failure. Circulation 1994; 90 : 195-203.

13. Hasegawa $\mathrm{K}$, Fujiwara $\mathrm{H}$, Doyama $\mathrm{K}$, Mukoyama M, Nakao K, Fujiwara $\mathrm{T}$ et al. Ventricular expression of atrial and brain natriuretic peptides in dilated cardiomyopathy. 
An immunohistocytochemical study of the endomyocardial biopsy specimens using specific monoclonal antibodies. Am J Pathol 1993; 142:107-116.

14. Levin ER, Gardner DG, Samson WK. Natriuretic Peptides. N Engl J Med 1998; 339:321-328.

15. Mukoyama M, Nakao K, Saito Y, Ogawa Y, Hosoda K, Suga $\mathrm{S}$ et al. Human brain natriuretic peptide, a novel cardiac hormone. Lancet 1990;335:801-802.

16. Burrell LM, Lambert HJ, Baylis BH. Effect of atrial natriuretic peptide on thirst and arginine vasopressin release in humans. Am J Physiol 1991;260:R475-R479.

17. Potter LR, Abbey-Hosch S, Dickey DM. Natriuretic peptides, their receptors, and cyclic guanosine monophosphate-dependent signaling functions. Endocr Rev 2006;27:47-72.

18. Yamamoto K, Bunett JC, Jaugasaki M. Superiority of brain natriuretic peptide is related to diastolic dysfunction in hypertension. Clin Exp Pharmacol Physiol 1997; 24A: 966-8.

19. Zhang SC, Dai Q, Wang JY. Effect of oral administration of lactulose on intestinal endotoxemia and cytokines in liver diseases. Chin J Hepatology 2000; 8: 185.

20. Sharara AI, Rockey DC. Gastroesophageal variceal hemorrhage. N Engl J Med 2001; 324: 669-81.

21. Goetze JP, Kastrup J, Pedersen F. Quantification of pro-B-type natriuretic peptide and its products in human plasma by use of an analysis independent of precursor processing. Clin Chem 2002;48:1035-42.

22. HenriksenJH, GøtzeGP, Fuglsang S, Christensen E, Bendtsen F, Møller S. Increased circulating pro-brain natriuretic peptide (proBNP) and brain natriuretic peptide (BNP) in patients with cirrhosis: relation to cardiovascular dysfunction and severity of disease. Gut. 2003 October; 52(10): 1511-1517

23. Goetze JP, Kastrup J. Plasma pro-brain natriuretic peptides are strong biochemical markers in clinical cardiology. Scand J Clin Lab Invest 2001;61(suppl 234): 47-51

24. Suzuki H, Stanley A.J. Current management and novel therapeutic strategies for refractory ascites and hepatorenal syndrome. QJM: $A n$ International Journal of Medicine 2001;94 (6): 293-300.

25. McCullough PA, Omland T, Maisel AS. B-type natriuretic peptides: A diagnostic breakthrough for clinicians. Rev Cardiovasc Med 2003; 4:7280.

26. Woo JJ, Koh YY, Hee , Kim J, Chung JW, Chang KS, Hong SP. N-terminal Pro B-type Natriuretic Peptide and the Evaluation of Cardiac Dysfunction and Severity of Disease in Cirrhotic Patients. Yonsei Med J 2008; 49(4):625 $-631$.

27. Jaffe A. Use of Plasma Brain Natriuretic Peptide Concentration to Aid in the Diagnosis of Heart Failure. Mayo Foundation for Medical Education and Research (MFMER) 2003;28(12).

28. Hans Peter Brunner-La Rocca, Wolfgang Kiowski, David Ramsay and Gabor Sütsch. Therapeutic benefits of increasing natriuretic peptide levels. Cardiovascular Research 2001;51 (3): 510-520.

29. LangenickelT., PagelI., HohnelK., DietzR., WillenbrockR. Differential regulation of cardiac ANP and BNP mRNA in different stages of experimental heart failure. Am. J. Physiol. Heart Circ. Physiol 2000; 278:H1500-H1506

30. Pornpen Srisawasdi, PhD1, Somlak Vanavanan, MSc1, Charaslak Charoenpanichkit, MD2 and Martin H. Kroll, MD. The Effect of Renal Dysfunction on BNP, NT-proBNP, and Their Ratio. Am J Clin Pathol. 2010 Jan; 133(1):1423.

31. Wong F, Tobe S, Legault L, Logan AG, Skorecki K, Blendis LM. Refractory ascites in cirrhosis: roles of volume expansion and plasma atrial natriuretic factor level elevation. Hepatology. 1993 Sep; 18(3):519-28. 